\title{
Use of chemical etching of CR-39 foils at elevated temperature for fast neutron personnel monitoring in India
}

\author{
Deepa Sathian ${ }^{1 *}$, Rupali Rohatgi ${ }^{1}$, V Jayalakshmi ${ }^{1}$, P K Marathe $^{1}$, Sarala Nair ${ }^{1}$, \\ R V Kolekar ${ }^{2}, G_{\text {Chourasiya }}{ }^{1}$ and S Kannan ${ }^{1}$ \\ ${ }^{1}$ Personnel Monitoring Section, Radiological Physics and Advisory Division, Bhabha Atomic Research Centre, \\ Mumbai-400 094, India \\ ${ }^{2}$ Radiation Safety Systems Division, Bhabha Atomic Research Centre, Mumbai-400 094, India
}

E mail : varikkuzhiyil@yahoo.co.in

\begin{abstract}
CR-39 Solid State Nuclear Track Detecting foils (SSNTD), along with $1 \mathrm{~mm}$ thick polyethylene radiator, sealed in triple laminated pouches, are used for country wide Fast Neutron Personnel Monitoring in India. With the present system of processing by elevated temperature electrochemical etching (ETECE) and evaluation using automatic image analysis, only 16 foils are processed at a time and it is useful over the dose equivalent range $0.2 \mathrm{mSv}$ to $10 \mathrm{mSv}$. It has been reported that, by processing CR-39 of good detection efficiency by chemical etching at elevated temperature, more numbers of foils can be processed simultaneously.

In the present study, CR-39 foils from Pershore Moulding (UK) have been chemically etched using $7 \mathrm{~N} \mathrm{KOH}$ under various conditions of temperature and etching durations and evaluated using high magnification microscope. The duration of chemical etching, has been optimized at a constant temperature of $60^{\circ} \mathrm{C}$ for chemical etching process. The characteristics of the chemically etched CR-39 foils are compared with the characteristics of the CR-39 foils processed by the existing system of ETECE and the detailed results are presented in the full text of the paper. It has been observed that by chemical etching process, the dose equivalent range of CR-39 foils can be extended above $60 \mathrm{mSv}$.
\end{abstract}

Keywords : CR-39 foils, SSNTD, chemical etching, fast neutron personnel monitoring, image analysis system.

PACS Nos. : $29.4 \mathrm{G} . \mathrm{n}, \mathrm{81}$.65.Cf, 87.53.Bn

\section{Introduction}

Presently, there is a wide spread use of Solid State Nuclear Track Detectors (SSNTD), for neutron personnel monitoring in the work place, due to their attractive characteristics such as non-fading of latent tracks in extreme humidity and temperature conditions and insensitivity to $\beta$ and $\gamma$ rays. In particular thermosetting plastic CR-39 is remarkable as a detector material for use as etched track neutron personnel dosimeters because of its high sensitivity to protons and its threshold energy of $100 \mathrm{keV}$ for fast neutrons. The systems [1] that are used operationally for neutron personnel dosimeters employing SSNTD are diverse, with a wide variety of etch process, read out systems and holder 
designs. There is little consistency between the systems partly due to the differences in detector materials and partly due to the processing and evaluation.

Country wide fast neutron personnel monitoring service is being conducted by Personnel Monitoring Section, RP \& AD, BARC, using, $625 \mu$ thick dosimetric grade CR-39 SSNTD, procured from Pershore Moulding, U K since last decade and its performance is well documented [2]. It has been reported that, if we have proton sensitive CR-39 of better detection efficiency, hundreds of foils can be processed simultaneously by chemical etching at elevated temperature $[3,4]$. Introduction of chemical etching at elevated temperatures for personnel monitoring, will have an advantage that processing of foils could be done at a larger scale.

In the present study, CR-39 foils have been chemically etched in a single step, using $7 \mathrm{~N} \mathrm{KOH}$ at $60^{\circ} \mathrm{C}$ for various duration of etching. The evaluation of chemically etched foils is done using high magnification optical microscope. The response is optimized based on the background, net track-density, the best signal to noise ratio, and the shape, size and clarity of the tracks formed for the different processing conditions employed. The response of the CR-39 foil chemically etched at elevated temperature and evaluated using high magnification optical microscope has been compared with response of $\mathrm{CR}-39$ foils processed by existing operational system (ETECE) at BARC.

\section{Experimental method}

Samples comprising of CR-39 foils of dimension $3 \mathrm{~cm} \times 3 \mathrm{~cm}$, sealed in triple laminate aluminized pouches with $3 \mathrm{~cm} \times 3 \mathrm{~cm} \times 1 \mathrm{~mm}$ thick polythene radiator in front, were used in the present study. Polythene radiator enhances sensitivity for track detection due to recoil proton and protects the foil from environmental radiation and from dust during handling.

For optimizing the processing conditions, twenty samples of foils with radiator, were exposed to $20 \mathrm{mSv}$ and another twenty samples were exposed to $1 \mathrm{mSv}$ neutron dose equivalent and an equal number of samples served as control foils. The irradiations were performed in air, in low scatter irradiation laboratory, at a distance of $50 \mathrm{~cm}$ with the radiator side facing the $1 \mathrm{Ci} \mathrm{Am-Be}$ neutron source with neutron yield of $2.5 \times 10^{6} \mathrm{n} / \mathrm{sec}$ and average neutron energy of $4.3 \mathrm{MeV}$. A set comprising of 4 exposed foils and 4 control foils were used for processing under different conditions. One set of the foils exposed to $1 \mathrm{mSv}$ along with the control foils were processed by ETECE and evaluated using an automatic image analysis system developed in BARC. The other sets exposed to $20 \mathrm{mSv}$ along with control foils, were processed by single step chemical etching at an elevated temperature of $60^{\circ} \mathrm{C}$, for different durations of 6 , 7, 8 and 9 hours and counted using the optical microscope. The response of CR-39 foils was optimized based on the lowest background counts, the best signal to noise ratio and well formed tracks for different conditions of processing. 


\subsection{Operating system for personnel monitoring at BARC :}

Electrochemical etching involves electrically stressing CR-39 foils using a high frequency sinusoidal electric field in a specially designed ECE cell. Careful choice of ECE parameters allow the neutron sensitivity and background of the CR-39 foil to be optimized. At the present processing of CR-39 SSNTD is carried out in two-step electrochemical process using a multi-foil etching chamber placed in an incubator maintained at $60^{\circ} \mathrm{C}$, in which 16 foils can be processed at a time. The foils are etched only on the side which is in contact with the radiator, using $7 \mathrm{~N} \mathrm{KOH}$ solution. The ECE cell is subjected to a high voltage of $1250 \mathrm{~V}$, for duration of 4 hours at a low frequency of $100 \mathrm{~Hz}$ followed by 40 minutes etching at high frequency of $3.5 \mathrm{kHz}$. The ECE cell is allowed to cool for 2 hrs. The foils are washed thoroughly, dried at room temperature overnight and evaluated.

The tracks were counted over one square centimeter $\left(1 \mathrm{~cm}^{2}\right)$ area of the foil by using an automatic image analysis system developed in BARC consisting of image frame - grabber, video camera and online PC [5]. Processing of foils using two-step electrochemical etching enables physical enlargement of the latent tracks from few nanometers to $125 \mu \mathrm{m}$ in diameter. Tracks are accepted as genuine if their areas and roundness fell within the acceptance criteria. The upper and lower limits for diameter of acceptable tracks were $75-125 \mu \mathrm{m}$ and for roundness 0.7 and 1.1 respectively.

\subsection{Chemical etching at elevated temperature (CE) :}

Samples of CR-39 exposed to $20 \mathrm{mSv}$ along with control foils were subjected to a single step chemical etching (CE) in $7 \mathrm{~N} \mathrm{KOH}$ at $60^{\circ} \mathrm{C}$ for durations ranging from 6 hrs to $9 \mathrm{hrs}$. The chemically etched foils were washed thoroughly and dried overnight in room temperature. The etched tracks were observed using an optical microscope with 200 times magnification. At this magnification one counting field encompasses an area of $0.01 \mathrm{~cm}^{2}$. The diameter of the tracks were in the range of $2-3 \mu \mathrm{m}$. Tracks are counted manually in 20 different fields around center of the detector (covering 0.2 $\mathrm{cm}^{2}$ ). In the unexposed detectors used for the assessment of background track density, 50 different fields were scanned. The tracks appeared as dark spots on a clear white background. The duration for chemical etching at $60^{\circ} \mathrm{C}$ has been optimized at 7 hours (Figure 1 and Table 1). Comparison of sensitivity, dose response and minimum measurable dose in both CE and ETECE methods at a temperature of $60^{\circ} \mathrm{C}$ using 7 $\mathrm{N} \mathrm{KOH}$ is presented in Table 2.

\subsection{Dose calibration of CR-39 foils :}

Reproducible and reliable measurements of neutron dose with an integrating detector depend on the soundness of the calibration procedure. For calibration, a $1 \mathrm{Ci} \mathrm{Am}-\mathrm{Be}$ standard neutron source was employed in a low scatter laboratory. Set of 8 foils each was exposed to neutron dose ranging from $1 \mathrm{mSv}$ to $60 \mathrm{mSv}$. One half of the foils 


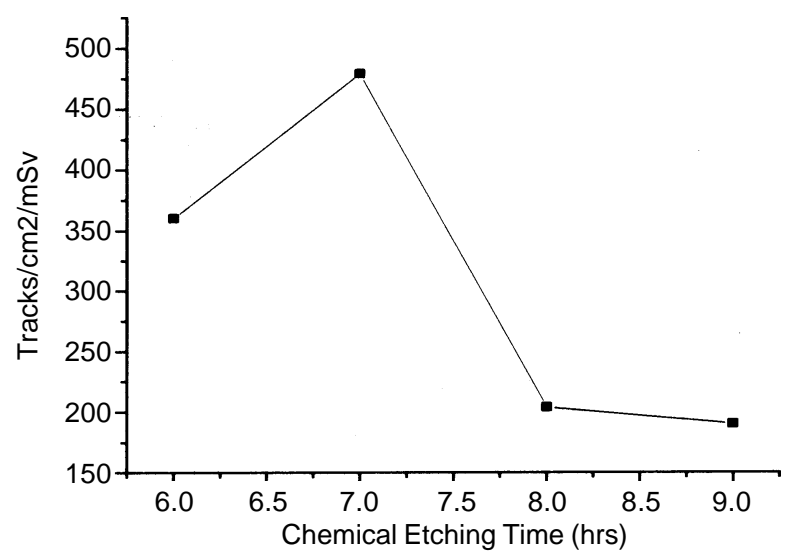

Figure 1. Optimized chemical etching time at $60^{\circ} \mathrm{C}$ and $7 \mathrm{~N} \mathrm{KOH}$.

Table 1. Effect of changes in chemical etching duration on background and sensitivity of CR-39 foils.

\begin{tabular}{llllllll}
\hline $\begin{array}{l}\text { Etching duration } \\
\text { (in } 7 \mathrm{~N} \mathrm{KOH}, \\
\text { at } 60^{\circ} \mathrm{C} \text { ) }\end{array}$ & $\begin{array}{l}\text { Control } \\
\text { Av. } \mathrm{cm}^{-2}\end{array}$ & $\begin{array}{l}\text { Std. dev. } \\
\sigma\end{array}$ & $\begin{array}{l}\mathrm{Av} . \mathrm{cm}^{-2} \\
(20 \mathrm{mSv})\end{array}$ & $\begin{array}{l}\mathrm{Net} \mathrm{cm}^{-2} \\
(20 \mathrm{mSv})\end{array}$ & $\begin{array}{l}\mathrm{Net} \mathrm{cm}^{-2} \\
\mathrm{mSv}^{-1}\end{array}$ & $\mathrm{~S} / \mathrm{N}$ ratio & $\begin{array}{l}\mathrm{MDL} \\
\text { (mR) }\end{array}$ \\
\hline 6 hours & 1145 & 25.07 & 8350 & 7205 & 360.25 & 7.29 & 418.0 \\
7 hours & 485 & 2.12 & 10060 & 9575 & 478.75 & 20.74 & 27.0 \\
8 hours & 250 & 0.77 & 4290 & 4040 & 202 & 17.16 & 23.0 \\
9 hours & 60 & 0.28 & 3860 & 3800 & 190 & 64.33 & 9.0 \\
\hline
\end{tabular}

Table 2. Response of CR-39 foils : chemically etched compared with electrochemically etched.

\begin{tabular}{lccccccccc}
\hline $\begin{array}{l}\text { Etching } \\
\text { method }\end{array}$ & $\begin{array}{c}\text { Avg. track } \\
\text { dia. in } \mu \mathrm{m}\end{array}$ & $\begin{array}{c}\text { Control } \\
\mathrm{Av} . \mathrm{cm}^{-2}\end{array}$ & $\begin{array}{c}\text { Std. dev. } \\
\sigma\end{array}$ & $\begin{array}{c}\mathrm{Av} . \mathrm{cm}^{-2} \\
\text { for } 1 \mathrm{mSv}\end{array}$ & $\begin{array}{c}\text { Std. dev. } \\
\sigma\end{array}$ & $\begin{array}{c}\text { Net. cm } \\
\mathrm{mSv}^{-1}\end{array}$ & $\begin{array}{c}\text { Std. dev. } \\
\sigma\end{array}$ & $\begin{array}{c}\mathrm{S} / \mathrm{N} \\
\text { ratio }\end{array}$ & $\begin{array}{c}\mathrm{MDL} \\
(\mathrm{mR})\end{array}$ \\
\hline ETECE & 95.75 & 15 & 2.98 & 110 & 4.50 & 95 & 5.39 & 7.3 & 15.0 \\
$\begin{array}{l}\text { Chemically } \\
\text { etched }\end{array}$ & 2.5 & 479 & 21.2 & 1523 & 34.45 & 1044 & 140 & 3.15 & 27.0 \\
\hline
\end{tabular}

were processed and counted by CE method and the other half by ETECE method. Dose response of CR-39 for chemically etched CR-39 foils from $1-60 \mathrm{mSv}$ is indicated in Figure 2 and Table 3. The curve shown represents the polynomial fit of the data. The calibration factor was $1031 \pm 100$ tracks $\mathrm{cm}^{-2} \mathrm{mSv}^{-1}$ for exposures up to 10 $\mathrm{mSv}$ and $823 \pm 282$ tracks cm $\mathrm{mSv}^{-1}$ for exposures $10 \mathrm{mSv}$ to $60 \mathrm{mSv}$ for CE (Figure 3 and 4) and $95 \pm 15$ tracks $\mathrm{cm}^{-2} \mathrm{mSv}^{-1}$ for ETECE (Figure 5).

\section{Results and discussion}

For ETECE only 16 foils can be etched at a time. Typical track densities due to Am-Be neutrons are approximately $100 \mathrm{~cm}^{-2} \mathrm{mSv}^{-1}$ although the actual values depend on the radiator, etching conditions used, thickness of the detector and shape and size 


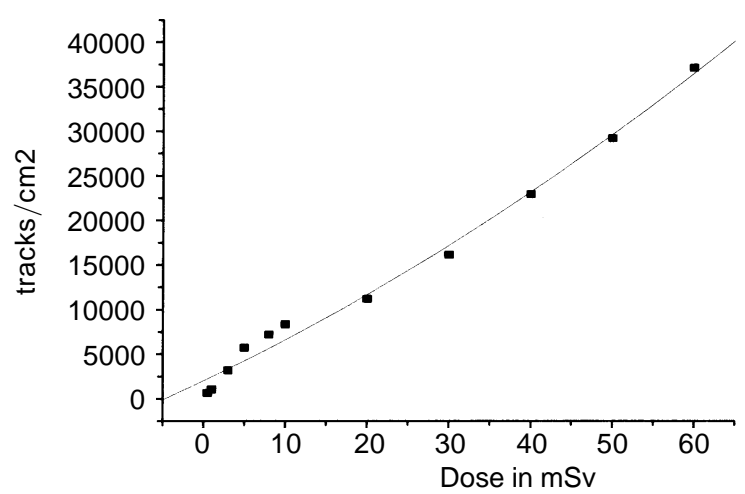

Figure 2. Dose response CR-39 for chemically etched CR-39 foils (1 - $60 \mathrm{mSv})$.

Table 3. Dose response of chemically etched CR-39 foils.

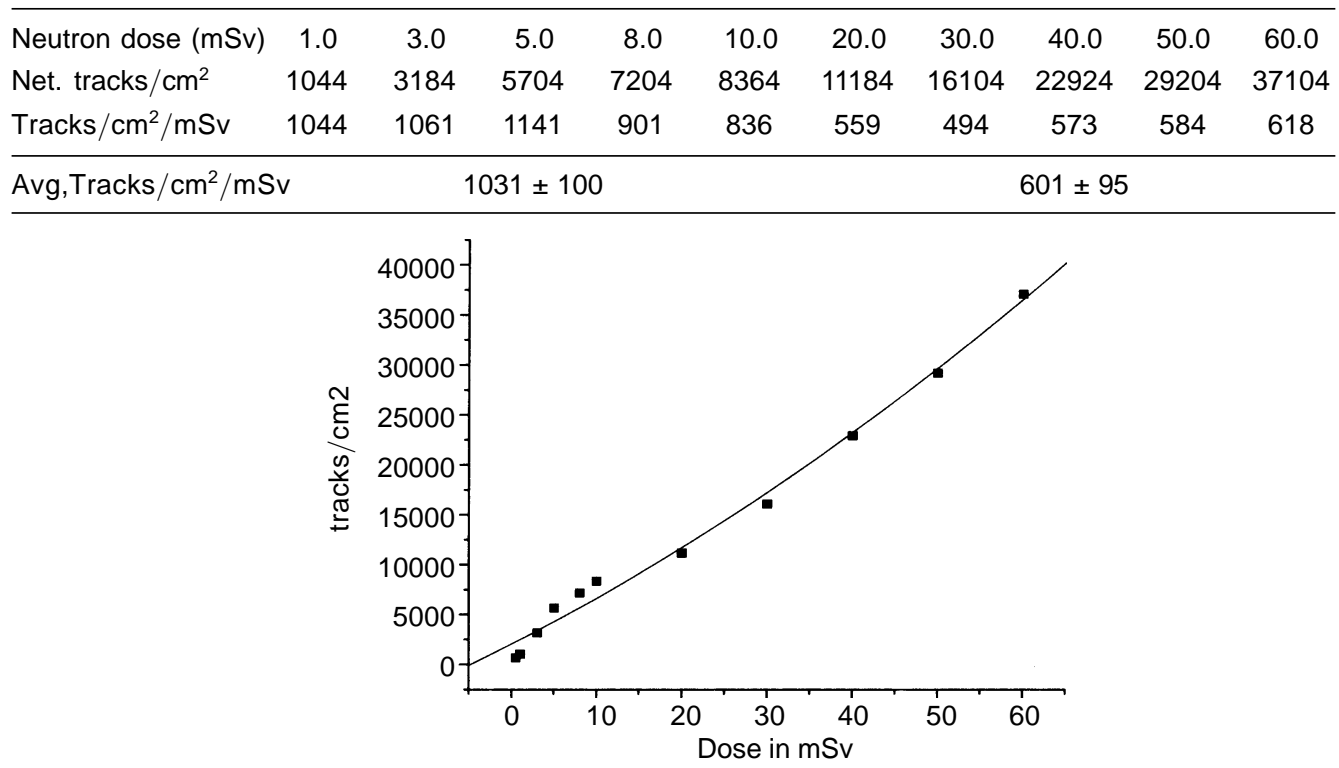

Figure 3. Dose response of chemically etched CR-39 foils $(1-60 \mathrm{mSv})$.

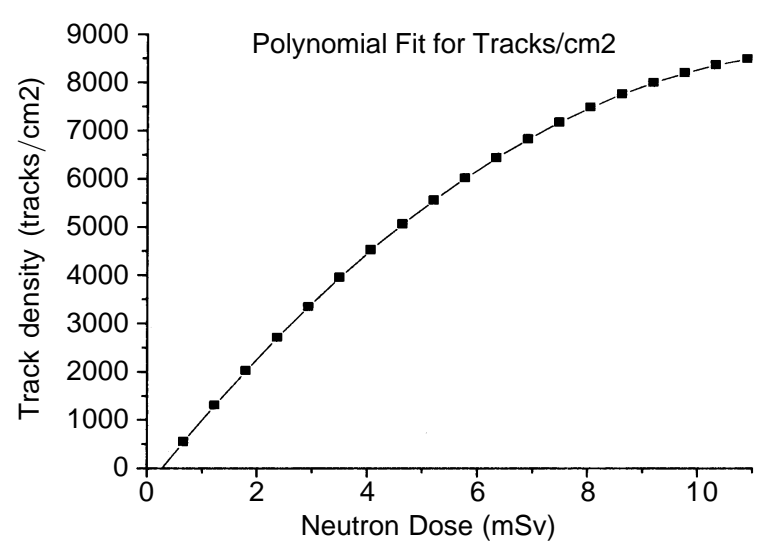

Figure 4. Dose response of chemically etched CR-39 foils $(<10 \mathrm{mSv})$. 
criteria used to identify tracks in image analysis system. The minimum dose equivalent that can be measured above the background is $0.15 \mathrm{mSv}$. The track diameter for ETECE is in the range of $75-125 \mu \mathrm{m}$ and with the limitations of our present automated image analysis system there is overlapping of tracks above $10 \mathrm{mSv}$ hence, the dose response curve gets saturated (Figure 5).

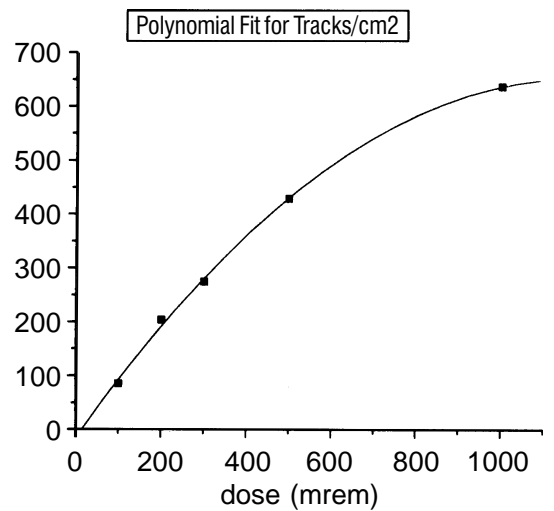

Figure 5. Dose response of CR-39 foils etched in ETECE.

The optimum duration of chemical etching (CE) for the CR-39 at $60^{\circ} \mathrm{C}$ in $7 \mathrm{~N}$ $\mathrm{KOH}$ solution was 7 hours (Figure 2, Table 1) and the MDL for CE is $0.27 \mathrm{mSv}$. The diameter of tracks in chemical etching are of the order of 3 microns and the magnification offered by the read out system (microscope) is 200 times. The etching efficiency in CE process is 10 times greater than in ETECE process hence the dose response curve for CE process goes beyond $60 \mathrm{mSv}$ (Figure 2). This extension of the dose range by chemical etching will be useful in the estimation of over exposures i.e., in cases very high doses are encountered in fast neutron personnel monitoring.

\section{Conclusion}

The chemical etching process is simple, as it requires no high voltage power supply and can be useful for etching foils in a large scale. Though chemical etching process has several advantages, the track counting using an optical microscope is more time consuming and cumbersome. However by introducing an optical microscope, mechanically automated with PC based image analysis system having compatible software, chemical etching of CR-39 will be a better option for personnel monitoring where large numbers of samples are to be processed and analyzed.

For implementation of chemical etching at high temperature for personnel monitoring, it is required that energy calibration is established for the chemical etching operational system.

\section{References}

[1] R J Tanner, D T Bartlett, and L G Hager Radiation Measurements 40549 (2005)

[2] M P Dhairyawan, P K Marathe and O P Massand Radiation Measurements 36435 (2003) 
[3] J R Harvey and A R Weeks Radiation Protection Dosimetry 2089 (1987)

[4] J R Harvey, A P French, M Jackson, M C Renouf and A R Weeks Radiation Protection Dosimetry 70149 (1997)

[5] Y V Rao, S Kar, G Valli, D G Joshi, V K Chaddaa, R K Nigam, O P Massand, M P Dhairyawan and P K Marathe Image Analysis System for Automation in Fast Neutron Personnel Monitoring using CR-39

Solid State Track Detector, International Conference on Automation ICAUTO-95 (Indore, India) (1995) 